\title{
QUEEN'S
UNIVERSITY
BELFAST
}

\section{Resistivity and Induced Polarization Monitoring of Biogas combined with Microbial Ecology on a Brown field Site}

Mendonça, C. A., Doherty, R., Debellis Amaral, N. D., McPolin, B., Larkin, M. J., \& Ustra, A. (2015). Resistivity and Induced Polarization Monitoring of Biogas combined with Microbial Ecology on a Brown field Site. Interpretation (Society of Exploration Geophysicists), 3(4), SAB43-SAB56. https://doi.org/10.1190/INT-20150057.1

Published in:

Interpretation (Society of Exploration Geophysicists)

Document Version:

Peer reviewed version

Queen's University Belfast - Research Portal:

Link to publication record in Queen's University Belfast Research Portal

Publisher rights

( 2015 Society of Exploration Geophysicists and American Association of Petroleum Geologists. All rights reserved.

\section{General rights}

Copyright for the publications made accessible via the Queen's University Belfast Research Portal is retained by the author(s) and / or other copyright owners and it is a condition of accessing these publications that users recognise and abide by the legal requirements associated with these rights.

Take down policy

The Research Portal is Queen's institutional repository that provides access to Queen's research output. Every effort has been made to ensure that content in the Research Portal does not infringe any person's rights, or applicable UK laws. If you discover content in the Research Portal that you believe breaches copyright or violates any law, please contact openaccess@qub.ac.uk. 


\section{Interpretation}

\section{Resistivity and Induced Polarization Monitoring with Microbial Ecology of Biogas Dynamics on a Brownfield Site}

\begin{tabular}{|c|c|}
\hline Journal: & Interpretation \\
\hline Manuscript ID: & INT-2015-0057 \\
\hline Manuscript Type: & Characterization and monitoring of subsurface contamination \\
\hline Date Submitted by the Author: & 17-Mar-2015 \\
\hline Complete List of Authors: & $\begin{array}{l}\text { Mendonça, Carlos; University of Sao Paulo, Department of Geophysics } \\
\text { Doherty, Rory; The Queen's University of Belfast, Environmental } \\
\text { Engineering Research Centre } \\
\text { Amaral, Nathan; University of Sao Paulo, Department of Geophysics } \\
\text { McPolin, Blathnaid; The Queen's University of Belfast, Environmental } \\
\text { Engineering Research Centre } \\
\text { Larkin, Michael; The Queen's University of Belfast, Environmental } \\
\text { Engineering Research Centre } \\
\text { Ustra, Andrea; University of Sao Paulo, Department of Geophysics }\end{array}$ \\
\hline Keywords: & electrical/resistivity, time-lapse \\
\hline Subject Areas: & $\begin{array}{l}\text { Near-surface, ground penetrating radar, environmental, and engineering } \\
\text { applications }\end{array}$ \\
\hline
\end{tabular}


Resistivity and Induced Polarization Monitoring with Microbial Ecology of Biogas Dynamics on a Brownfield Site

by

Carlos A. Mendonça ${ }^{1}$, Rory Doherty ${ }^{2}$, Nathan D. Amaral ${ }^{1}$, Blathnaid McPolin ${ }^{2}$, Michael J. Larkin ${ }^{3}$, Andrea Ustra ${ }^{1}$

1- Department of Geophysics, University of São Paulo,Rua do Matão, 1226, São Paulo, SP CEP 05508-090, Brazil.

2- Environmental Engineering Research Centre, School of Planning Architecture and Civil Engineering, The Queen's University of Belfast, Belfast BT9 5AG, UK 3- School of Biological Sciences, The Queen's University of Belfast, Belfast BT9 5AG, UK

To be submitted to the INTERPRETATION

Special issue "Characterization and monitoring of subsurface contamination" 


\begin{abstract}
The accumulation of biogenic greenhouse gases (methane, carbon dioxide) in organic sediments is an important factor in the redevelopment and risk management of many brownfield sites. Correct site characterization requires the monitoring of biogas levels and the identification of free gas phases and pathways that allow its migration and release at the ground surface. Gas pockets trapped in soils and sediments have contrasting properties with the surrounding porous media that favours their detection using remote sensing geophysical methods. We present a case study in which pockets of gas were identified by intercepting multi-level monitoring wells and their lateral continuity monitored with resistivity sections over a period of months. An interpretation procedure based on the Archie's law was developed to evaluate changes in water and gas content with respect to a mean background medium. Induced polarization data are used to account for errors in applying Archie's law due to contribution of surface conductivity effects in common geological media. Mosaics defined by changes in water saturation allow the recognition of gas migration and groundwater infiltration routes and the association of gas and groundwater fluxes. Inference on flux patterns were analysed by taking into account pressure measurements in trapped gas reservoirs and by metagenomic analysis of the microbiological content retrieved from suspended sediments when groundwater was sampled in multi-level monitoring wells. A holistic conceptual model of physical and microbiological subsurface processes was developed suggesting that biogas trapped at depth may have the ability to quickly travel to surface.
\end{abstract}

key words: free-gas phase, methane, resistivity imaging, induced polarization. 


\section{INTRODUCTION}

Organic material confined in anaerobic environments (sediments or landfills) is a source of biologically produced methane or biogas, it is a greenhouse gas, and therefore of great importance in global studies related to climate change. The organic matter is biodegraded anaerobically through a series of fermentation and methanogenesis steps that generates carbon dioxide and methane as major products (Christensen, 2010). Once initiated, the methanogenesis process produces biogas and as the pressure grows a free-gas phase (FGP) forms by expelling pore water, filling rock and soil interstices. The FGP tends to move upward and escapes at the surface, but it can be trapped by impermeable layers and develop over-pressured accumulations (Mendonça et al., 2015). Methane is also an asphyxiant, flammable, and potentially explosive gas in mixtures containing $5-15 \%$ of air. Because it is lighter than air, it tends to occupy void spaces in porous media and beneath buildings as it escape at the ground surface posing risks to human health.

Different transport mechanisms drive FGP transport in the subsurface as it moves towards the ground surface. Transport may occur (Rosenberry et al., 2006; Stamp et al, 2013) by i) diffusion through the groundwater column, ii) channelling along natural conduits made by porous tissue of vascular plants, iii) buoyancy of gas bubbles along pore network. The third mechanism is termed as ebullition and has been observed in lakes (Walter et al., 2006), inland water sheds (Joyce and Jewell, 2003; Bastviken et al., 2011) and captured in trapping devices for flux evaluation ( $\mathrm{Yu}$ et al., 2014). Ebullition is periodic and may release large gas volumes over short time scales (Glaser et al., 2004). Ebullition is often conditioned by changes in atmospheric pressure; it may be triggered in shallow soils (1-2 $\mathrm{m}$ deep) as the atmospheric pressure increases, 
but with little effect in deeper layers, that instead show upward movement of the FGP when the atmospheric pressure drops (Comas et al., 2011).

The dangers posed by biogas accumulations in the subsurface make noninvasive geophysical methods to characterize biogas accumulations on brownfield sites attractive. Geophysical methods to monitor FGP in peatlands have been the object of many field and laboratory studies. Ground penetrating radar (GPR) was applied to estimate vertical distribution of shallow FGP pockets based on the fact that such accumulations modify the soil dielectric properties that are detectable by changes in the propagation velocity of the electromagnetic waves (Comas et al., 2008,2011; Parsekian et al., 2011). Two-dimensional resistivity has been applied to characterize the build up and ebullition of FGP under different meteorological conditions and peatland scenarios, with different composition and cover by vascular plants (Kettridge et al., 2011). Timelapse ERT was applied to identify recharge zones in catching peatlands and determine factors conditioning the resistivity of such environments, the temperature being the most important one in shallow levels (Musgrave and Binley, 2011). Higher flow venting of soil $\mathrm{CO}_{2}$ seems to be associated with negative $\mathrm{SP}$ anomalies over zones with lower resistivity, attributed to enhanced porosity due to mineral dissolution (carbonates) and changing of water bulk resistivity (Schütze et al., 2013).

In this particular case as urban development encroached over wetlands along stretched fluvial plains and coastal areas, a set of anthropogenic activities favouring the generation and trapping of biogenic gases was introduced. Firstly, the ubiquitous pollution from unregulated disposal of organic rich wastes that were freely discharged in lowland aqueous. Secondly, the filling and levelling of lowlands, a basic practice in flood control and land reclamation in densely populated cities, which buried geogenic sediments and anthropogenic deposits (wastes) rich in organic carbon. In addition, soil 
compaction and the impermeable covering of the ground surface created sealing structures that favour the entrapment of over pressured FGP biogas reservoirs. This poses risks to those who now occupy the redeveloped land since the reclamation activity has created conditions that could result in the release of entrapped biogas.

This paper presents a case study in which resistivity and Induced Polarization (IP) data are applied to study a test site with trapped FGP reservoirs previously identified with multi-level monitoring wells and geophysical data (Mendonça et al., 2015). A shallow biogas reservoir (FGP1) has its pressure equilibrated to that of the atmosphere, but a deeper reservoir (FGP2) is under pressure due to the confinement into a sandstone lens embedded into the organic-rich, clay layer that acts as the source of the biogas (Figure 1). Due to the pressure gradient in the reservoirs, significant changes in subsurface properties should be expected, in response to ascendant (gas escaping) and descendant (water recharge) coupling of fluid fluxes. However, a set of resistivity sections acquired in 2012 and 2013 revealed an impressive uniformity in subsurface resistivity. This prevented further investigations of short temporal variations (daily or weekly) but highlighted the need to identify subtle temporal variations recorded by resistivity data and to define spatially what portions of the subsurface are most affected. We developed a procedure to track smaller temporal variations in resistivity data to detect variations in FGP content, possible pathways connecting FGP reservoirs, areas likely to have biogas escaping at surface, and changes associated to ground water infiltration. This paper presents concepts about resistivity and IP methods, followed by the introduction of a formulation to infer variations in water saturation from resistivity data (IP data correcting for surface conductivity effects) and by a description of a case study developed at a test site with FGP reservoirs of biogenic gases, with results 
interpreted with independent data from multi-level sampling, gas analyses, and microbiological data.

\section{THEORETICAL ASPECTS}

\section{Resistivity \& Induced Polarization}

Resistivity and IP methods are based on the measurement of electric fields established during injection of harmonic or squared-like low frequency currents in probed geological medium. The experimental setup to excite and measure the earth response requires two pairs of electrodes; one to inject current (current electrodes), the other to measure medium response in terms of electric potentials (potential electrodes). Current and potential electrodes can be distributed along profiles or grids at the ground surface (Revil et al., 2012; Loke et al., 2013), within adjacent boreholes (Pidlisecky et al., 2006; Danielsen and Dahlin, 2010), or making combinations between surface and borehole electrodes (Bergmann et al., 2012; Power et al., 2015; Mendonça et al., 2015). Some arrays are specifically termed (e.g., schlumberger, wenner, dipole-dipole) but unusual configurations or multiple combination of arrays can used in modern surveys with computer assisted data acquisition (Loke et al., 2013).Resistivity measurements are taken by injecting a current $I$ (usually up to 1-2 A) and measuring a voltage $V_{p}$ (up to a volt) that is established in response. Ratio $V_{p} / I$ is termed as transfer resistance and can be regarded as the earth response. The medium apparent resistivity is obtained by multiplying the transfer resistance by a geometrical factor accounting for distances and layout of electrodes (Revil et al., 2012).

IP data can be obtained from the same experimental setup of resistivity measurements, but measuring a different sort of electric potentials (Slater and Lesmes, 2002; Revil et al., 2012). In the frequency domain, the driven current is harmonic (frequency range of $\mathrm{mHz}$ to $\mathrm{kHz}$ ) with measurements of transfer resistances (or apparent 
resistivity) and time-lag (phase) between the response potential and the applied current as a function of the frequency. The extension of these measurements to a frequency spectrum is termed as spectral IP, with conductivity measurements expressed as complex quantities (in and out of phase terms) or by means of amplitude and phase. In time domain measurements, a squared-like current is applied with steps of on-offreverse-off cycles, with potential measurements taken in the off stages and averaged along multiple cycles. Time domain results are usually expressed in terms of chargeability, defined as $M^{\prime}=M / \Delta t$ in which

$$
M=\frac{1}{V_{p}} \int_{t_{i}}^{t_{f}} V_{s} d t
$$

for $V_{s}$ as the residual voltage recorded at a time window $\Delta t=t_{f}-t_{i}$, after a delay-time $t_{i}$ when the injection of current was interrupted. The IP response expresses the ability of earth materials to temporarily store charge when excited by electrical currents.

Resistivity imaging or ERT (Earth Resistivity Tomography) is based on measurements of potential differences resulting from applied currents, using arrays of electrodes at the ground surface and/or in boreholes. For electrode arrays along a profile or confined into a vertical plane (surface-borehole configuration), a resistivity section representing the distribution of the earth material is provided by solving an inverse problem (Pidlisecky et al., 2007; Karaoulis et al., 2013; Loke et al., 2013). The aim of the inversion process is to calculate a model (or image) that provides data fitting to the observed data. Data fitting can be assessed by a functional, $Q(\mathbf{p})$, expressed in terms of the unknown parameters, $\mathbf{p}$, addressing the $N_{p}$ resistivity values, $p_{i}, i=1, \cdots, N_{p}$, for each $i$-th cell of the model. A set of $N_{d}$ measurements of apparent resistivity of transfer resistance can be organized in a data vector $\mathbf{d}_{o}$ of dimension $N_{d}$ in order to be comparable to model response $\mathbf{d}_{c} \equiv \mathbf{d}_{c}(\mathbf{p})$. The unknown model $\mathbf{p}$ can be iteratively determined such that residuals between $\mathbf{d}_{o}$ and $\mathbf{d}_{c}$ become minimum, meanwhile 
attending a set of physical constraints for the resistivity model encoded in $\mathbf{p}$. A solution for the unknown parameter can be found by minimizing a functional form such as

$$
Q(\mathbf{p})=\left\|\mathbf{d}_{o}-\mathbf{d}_{c}\right\|_{q}+\mu\left\|\mathbf{p}-\mathbf{p}_{0}\right\|_{q}
$$

in which $\mathbf{p}_{0}$ is an initial solution from which the non-linear problem minimizing functional $Q(\mathbf{p})$ are linearized and iteratively solved.

In equation $2, \mathbf{d}_{c} \equiv \mathbf{d}_{c}(\mathbf{p})$ evaluates the response of model $\mathbf{p}$, and $\mu$ is a regularizing parameter balancing data fitting quality against model departure from $\mathbf{p}_{0}$. Term $\|\cdot\|_{q}$ for $q \geq 1$ stands for generalized $q$-norm, $q=2$ standing for the Euclidean or L-2 norm and $q=1$ for the absolute or L-1 norm. In minimizing data misfit, the L-2 norm leads to least squares estimates (Pidlisecky et al., 2007; Karaoulis et al., 2013). For the model space the L-2 to model space $\mathbf{p}$ gives a smooth solution favoring resistivity distributions with gradational transitions, adequate when contacts between geologic unities are gradual. The use of L-1 in data fitting provides robust estimates that are less sensitive to error in data. When applied to the model parameter, the L-1 norm provides what is termed as "flat" solutions that favor models with contrasting resistivity but domains with rather uniform resistivity values (Loke et al., 2003; Farquharson, 2008). The flatness condition is then well suited when local geology prescribes abrupt contacts (Musgrave and Binley, 2011). The damping factor $\mu$ can be found iteratively by evaluating the norm of data residuals for a range of trial values. It starts from very small trial values providing best data fittingtuning it gradually higher until data fitting is abruptly degraded. An optimal value for $\mu$ can be set at the inflection point from which data fitting is degraded. This criterion implicitly assumes that $\mu$ can be enough small to honour data (e.g., by fitting it) but higher enough to interfere in the norm of parameter and, with this, provide model solution with lateral continuity. 
Mathematical operations to evaluate model response, $\mathbf{d}_{c}(\mathbf{p})$, involve the numerical solution of Poison equation,

$$
\nabla \cdot\left(\sigma \nabla \varphi_{\mathrm{EL}}\right)=-I\left(\delta\left(\mathbf{r}-\mathbf{r}_{+}\right)-\delta\left(\mathbf{r}-\mathbf{r}_{-}\right)\right)
$$

for potential $\varphi_{\mathrm{EL}}$ in response to bipolar current with intensity $I$, with plus and minus terminations at positions $\mathbf{r}_{+}$and $\mathbf{r}_{-}$standing for terminations with positive and negative poles of current. Once evaluated, potential values of $\varphi_{\mathrm{EL}}$ is selected for points with measurements and used to evaluate the transfer resistance or apparent resistivity. This model response can then be compared to real data set and the resistivity model iteratively updated to provide data fitting (Pidlisecky et al., 2006; Karaoulis et al., 2013). Model response for IP also implies the solution of a Poison equation to evaluate a potential $\varphi_{\text {IP }}$ by replacing medium property $\sigma$ in equation (3) by conductivity $\sigma^{\prime}$ such that (Oldenburg and Li, 1994)

$$
\sigma^{\prime}=\sigma(1-M)
$$

with $M$ standing for medium chargeability. The evaluation of IP potential $\varphi_{\text {IP }}$ requires then the knowledge of medium resistivity. In interpreting real data it requires iterative procedures starting from the inversion of resistivity data to determine a background resistivity/conductivity. Fixing $\sigma$ in equation 4, chargeability models, $M$, are iteratively obtained until model response from evaluating equation 3 with conductivity $\sigma^{\prime}$ reaches convergence, allowing data fitting (Oldenburg and Li, 1994; Li and Oldenburg, 2000).

\section{$\underline{\text { Macroscopic petrophysical model }}$}

The flow of current in saturated geologic media composed by minerals with no electronic conduction (graphite, metal sulphides) follows pathways along rock interstices filled with pore water and along charged interfaces coating the mineral 
framework (Leroy and Revil 2009; Jougnot et al. 2010;). In analogy with a pair of resistors in parallel (Vinegarand Waxman, 1984; Slater and Lesmes 2002), bulk and surface conductivities, $\sigma_{B}$ and $\sigma_{S}$, adds up to compose the medium conductivity, $\sigma_{0}$, as

$$
\sigma_{0}=\sigma_{B}+\sigma_{S}
$$

Bulk conductivity through pore water guards a power law dependency with porosity, $\phi$, (fraction of voids in a representative volume) and water saturation, $S$, (fraction of pore volume filled with water) as given by empirical Archie's law (Archie, 1942)

$$
\sigma_{B}=\phi^{m} S^{n} \sigma_{w}
$$

that prescribes a linear dependence between bulk conductivity, $\sigma_{B}$, and pore water conductivity, $\sigma_{w}$. Parameters $m$ and $n$ are empirically determined for each soil or rock type but usually are about to 2.00 to 2.15 , (Hamada, 2010). Surface conductivity, $\sigma_{S}$, is conditioned by mobility and charge density at the interface of rock forming minerals (Leroy and Revil, 2009;) and determines the medium response in IP measurements (e.g., Kemna et al., 2012). Surface conductivity has a frequency dependent response (de Lima and Sharma, 1992; Revil et al., 2012) that can be related to structured distribution of charge in the mineral interface (Jougnot et al., 2010; Revil and Florsch, 2010; Florsch et al., 2014). Because methane is the non-wetting phase, the emplacement of a FGP bubble in pore space preserves the properties of the mineral-fluid interface, in principle not affecting its surface conductivity.

Laboratory and field data describing macroscopic response of IP and resistivity measurements show that surface conductivity is equivalent to a quantity termed as normalized chargeability (Slater and Lesmes, 2002), given by

$$
M_{N}=M \quad \sigma_{0}
$$

such that $\sigma_{S} \approx M_{N}$.

In terms of resistivity $(\rho \equiv 1 / \sigma)$, equation 5 can be re-written as 


$$
\rho_{0}=\rho_{B} f
$$

with

$$
\rho_{B}=\phi^{-m} S^{-n} \rho_{w}
$$

and partition parameter, $f \equiv f\left(\rho_{S}, \rho_{B}\right)$ such that

$$
f=\frac{\rho_{S}}{\rho_{B}+\rho_{S}}=\frac{\sigma_{B}}{\sigma_{0}} .
$$

The partition parameter $f$ thus expresses the contribution of bulk conductivity in total rock conductivity. A value equal to 0.8 , for example, does mean that bulk conductivity contributes to $80 \%$ of medium conductivity, with the remaining $20 \%$ accounting for surface conductivity.

For cases in which medium porosity and water conductivity are time invariant, time changes in resistivity, $\rho_{1}, \cdots, \rho_{n}$, for time frames $t_{1}, \cdots, t_{n}$ can be attributed to changes in water saturation and/or in the conductivity partition. Invariance of porosity is a valid assumption for mature buried sediments but variable, and even dependent on size of gas bubbles in unconsolidated bogs. By assuming invariance of medium porosity and pore water conductivity, the resistivity for conditions prevailing in time $i$ is

$$
\rho_{i}=\phi^{-m} S_{i}^{-n} \rho_{w} f_{i}
$$

with saturation $S_{i}$ representing the water content at the $i$-th time frame. Assuming in addition $m$ as constant and $n=2$ (Hamada, 2010; Worthington, 2011), aquantity

$$
R_{i, k} \equiv\left(\frac{\rho_{i}}{\rho_{k}} \frac{f_{k}}{f_{i}}\right)^{1 / 2}
$$

can be defined to account water saturation change between time-frames $t_{i}$ and $t_{k}$ since

$$
R_{i, k} \equiv \frac{s_{k}}{S_{i}} \quad
$$

Parameter $R_{i, k}$ can be used to monitor relative changes in water saturation. Considering time-frames such that $t_{i}<t_{k}$, a resistivity change such that $R_{i, k}>1$ indicates that $S_{k}>S_{i}$, meaning that a larger fraction of the pore space was filled with water between 
time-shots $i$ and $k$. A change with $R_{i, k}<1$, otherwise, points to $S_{k}<S_{i}$, meaning that pore water was replaced by gas, either due to downward diffusion of atmospheric air or by upward migration of FGP generated in organic sediments. Pixel-by-pixel evaluation of parameter $R_{i, k}$ recognizes domains in which water saturation increases (water in) or diminishes (gas in). The mosaic created by connected domains shows the extension and continuity of subsurface portions most affected by variations in fluid content. In principle, such mosaics can be able to recognize flow paths for water recharge, gas release and possible relationships between water and gas flows.

\section{$\underline{\text { Biogas Generation and Microbial Ecology on Brownfield sites }}$}

Biogas formation on brownfield sites due to either anthropogenic or geogenic processes is the result of microbial activity, usually in the absence of oxygen, degrading organic matter. Microbial ecology techniques may be used to assess microbial communities and structure in a variety of applications from medical sciences ( $\mathrm{Li}$ et al. 2014) to the ocean floor (Orcutt et al. 2011) and contaminated environments (Ferguson et al. 2007). The microbial ecology of biogas formation may be dependent on a variety of factors such as the type and nature of the organic matter (anthropogenic - municipal waste, or geogenic - organic rich sediments), the porous media, and the groundwater chemistry. Biogas is a mixture of methane $\left(\mathrm{CH}_{4}\right)$ and carbon dioxide $\left(\mathrm{CO}_{2}\right)$ that form the end point of a series of steps of organic matter biodegradation. The methanogenic biodegradation of complex organic substrates is widespread in nature where the environment is anoxic.

The overall process itself requires at least four distinct physiological groups of microbes. A diverse range of primary fermenting bacteria channel a wide range of biological polymers such as proteins and lipids and ferment them to products such as 
alcohols and organic acids, $\mathrm{H}_{2}$ and $\mathrm{CO}_{2}$. These are the substrates for two major groups of methanogenic Archaea. The hydrogenotrophic methanogens convert $\mathrm{H}_{2}$ and $\mathrm{CO}_{2}$ to methane, whereas the acetoclastic methanogens degrade acetate to methane directly (Weiland 2010). Three types of methanogenic pathways are known: hydrogenotrophic $\mathrm{CO}_{2}$-reduction, the acetoclastic reaction noted above and methyl-group reduction. Many methanogens appear capable of hydrogenotrophic methanogenesis that is closely linked to syncotrophic anaerobic acetate oxidation, whereas two groups Methanosarcina and Methanosaeta perform the acetoclastic reaction. This limited metabolic diversity hides much wider phylogenetic diversity (Liu and Whitman 2008). Cultured methanogens are grouped into five orders based upon their phylogeny and phenotypic properties. In addition, uncultured methanogens are detected in many anoxic environments. Metagenomics is a powerful approach that analyses microbial communities regardless of whether they can be cultivated in the lab or not. It utilises the DNA extracted directly from environmental samples such as soils or groundwater and allows a survey of whole microbial community present (Daniel 2005). Once the DNA has been extracted, it is amplified using polymerase chain reaction (PCR) techniques prior to sequencing, annotation and analysis of the metagenome. The aim here is to link the microbial community structures at this particular brownfield site and to ask questions regarding the environments of biogas formation in the subsurface. This information on microbial ecology may provide insights to the formation and consequently our approach to monitoring of the biogas in the subsurface.

\section{MATERIALS AND METHODS}

$\underline{\text { Test site geology }}$

The feasibility of applying resistivity data to identify patterns in water saturation changes was investigated in a field study at a test site situated at a former flood plain of 
Tietê River, in São Paulo, Brazil (Mendonça et al., 2015). At this test site a source of trapped FGP is a thick ( $\sim 6 \mathrm{~m})$ layer with organic clayey sediments (organic carbon up to $40 \%$ in weight) deposited along an abandoned meander of the river. This layer was covered with anthropogenic deposits produced when the course of the river was lowered and aligned. Dredged sediments in the covering layer were pumped into a dykeencircled pond of about 25 hectares and settled to dry, generating a $4 \mathrm{~m}$ high terrace. For decades this site was an abandoned brownfield site until public developments for green parks and schools were made. Occurrences of trapped methane were observed yet during geotechnical studies, requiring specialized building design, permanent monitoring facilities, and ventilating systems as corrective measurements.

The test site was established in 2011 at a representative place of the developed land by installing three multilevel monitoring wells each one with 15 sampling ports 0.6 m spaced, able to sample gas and water until $8.6 \mathrm{~m}$ depth (Mendonça et al., 2015). A set of 5 electrodes were permanently installed downhole to improve sensitivity in resistivity imaging in complementing to non-permanent electrodes deployed at the ground surface. Resistivity images attempted not to reconstruct water and gas fluxes in short time-scales but instead, to verify if major seasonal changes in resistivity were observable. Samples of sediments from continuous direct-push coring were analyzed for total content of organic carbon and grain size analysis by laser diffraction (Mendonça et al., 2015). Two FGP reservoirs were intercepted by monitoring wells (Figure 1) and their lateral continuity outlined as more resistive targets $(80-110 \mathrm{ohm} . \mathrm{m})$ with respect to organic sediments (5-25 ohm.m) in which they are embedded. The higher resistivity contrast of FGP unities can be attributed to rather high specific conductivity of pore water $(\sim 0.5$ $\mathrm{mScm}^{-1}$ ) as sampled by multi-level sampling ports of the monitoring wells (Mendonça et al., 2015). An occurrence of over-pressured FGP was identified in a permeable sandy 
lens embedded at the bottom of the organic rich sediments. On average, the pressureof this reservoir is 4 to $5 \%$ above atmosphere pressure when measurements were taken. The pressure of the shallower reservoir, otherwise, is equilibrated to the atmosphere, suggesting that in addition to trapped accumulations there are reservoirs well connected to the ground surface, possibly releasing their content as the atmosphere pressure fluctuates. A higher risk in land use is posed by the over-pressured accumulations that in principle could suddenly release large volumes of biogas that could quickly occupy non-ventilated rooms or underground spaces with asphyxiant and potentially explosive atmospheres $(5-15 \%$ of methane mixed with air). The gas composition in both reservoirs is enriched in $\mathrm{CH}_{4}$, about $37-45 \%$ of $\mathrm{CO}_{2}$ to $55-63 \% \mathrm{CH}_{4}$, with traces of $\mathrm{H}_{2} \mathrm{~S}$ ( $30 \mathrm{ppm})$. Vadose zone oxygen decays quickly to trace levels within a meter depth. The piezometric surface is relatively flat, with a hydraulic gradient of 0.0082 towards the river. The high permeability $\left(12-62 \mathrm{~cm}^{\text {day }}{ }^{-1}\right)$ of the anthropogenic unit does not work as an efficient sealing unit for FGP volumes reaching the vadose zone, and also facilitates water aerobic water recharge and removal/dispersal of stagnant FGP to the atmosphere.

\section{$\underline{\text { Resistivity and IP data }}$}

Resistivity surveys were repeated in the years of 2012 and 2013 with a set of 28 electrodes $2 \mathrm{~m}$ spaced at the ground surface and 5 electrodes permanently installed downhole (Figure 1). This set of 33 electrodes was used to obtain resistivity and IP data with wenner and dipole-dipole arrays programmed in a computer assisted resistivimeter (Sting R1-IP, AGIUSA) totalling 460 measurements in each survey. Contact resistance was kept below 1-1.5 kohm in all measurements, discarding data with repeat error above $3 \%$. The current waveform had stages on-off-reverse-off with intervals of $2 \mathrm{~s}$, with IP measurements in the rest interval during $100 \mathrm{~ms}, 200 \mathrm{~ms}$ after interruption, and 
this cycle repeated fourth. As shown in Figure 2, there are minor changes in the apparent resistivity data measured in 2012 (March, May, July) and 2013 (April, June). These data sets ( 6 in total) were inverted using a regularized least squares optimization method EarthImager 2D (AGIUSA, 2009) with forward problem being solved by the finite difference method for mesh with cells $\geq 1 \mathrm{~m}$ (half of surface electrode spacing), increasing at a rate of $1 \%$ for each layer in depth. Pseudo resistivity sections were used as starting models, with data inversion proceeding interactively until convergence. The resistivity model was constrained by positivity and flatness criteria, the last one by minimizing the L-1 norm of the model parameter.

All data sets were inverted with a same regularization parameter $(\mu=100)$, chosen according results in Figure 3. This parameter expresses the trade-off between model roughness and data misfit. An unsuited low value prescribed for this parameter provides good data fitting but noisy resistivity model, in which adjacent cells of the model showing unrealistic oscillations in resistivity values. An unsuited higher value, otherwise, gives continuity between cells but degrades data fitting beyond error margin of experimental data. Since $\mu$ bounds the resistivity model and introduces a smoothness dose to the models, it cannot be established arbitrarily for each data set. To compare resistivity models from different data sets a common smoothness dose must be applied. A shown in Figure 3, a proper value for $\mu$ can be chosen by making trade-off curves in fitting each data set. A well suited value $\mu$ is defined by the inflection point beyond that data misfit in no more flat but instead grows sharply. After this inflection point, data fitting is arbitrarily conditioned by the choice for parameter $\mu$ at the expenses of higher data misfit. Figure 4 shows data fitting of measured and model response data, showing good adherence between then. 


\section{$\underline{\text { Microbial DNA extractions }}$}

Groundwater samples were stored at $4^{\circ} \mathrm{C}$ and filtered to capture suspended sediment within $24 \mathrm{hrs}$ of sampling (Whatman $0.2 \mu \mathrm{m}$ ) to trap microbial DNA. The filters were then frozen and shipped to Queen's University Belfast for DNA extraction. DNA was extracted with $0.5 \mathrm{mg}$ of sediment filtrate was used for each extraction Powersoil DNA Isolation kit (Mo Bio), extractions for each location were carried out in triplicate and the DNA was pooled. DNA concentrations were quantified using a nanodrop (ND1000 V3.5.2) with pyrosequencing of the $16 \mathrm{~s}$ rDNA bacterial and archaeal genes.

\section{Bacterial Pyrosequencing}

A 2-step polymerase chain reaction (PCR) approach was taken to amplify $16 \mathrm{~S}$ rRNA gene of bacteria. The amplicons were prepared as previously described (Berry et al. 2011) using universal primers for the V6-V9 variable regions, 909F and 1492R including adaptors (LibL/A and LibL/B) and tags (Hamady et al. 2008). PCR was carried out in a final volume of $25 \mu 1$ containing $0.4 \mu \mathrm{m}$ of each $16 \mathrm{~S}$ primer (HPLC pure from IDT, Inc.) and $1 \mu \mathrm{l}$ of DNA template. PCR conditions were $95^{\circ} \mathrm{C}$ for $4 \mathrm{~min}$ and 25 cycles of $95^{\circ} \mathrm{C}$ for $30 \mathrm{~s}, 52^{\circ} \mathrm{C}$ for $45 \mathrm{~s}, 72^{\circ} \mathrm{C}$ for 1 min $30 \mathrm{~s}$, and a final extension of $72^{\circ} \mathrm{C}$ for $7 \mathrm{~min}$. PCR product was used as the template in the second round amplification (1:25 dilution) where fusion primers were used (adaptors (LibL/A and LibL/B), tags (Hamady et al. 2008) and 16S primers). PCR conditions were $95^{\circ} \mathrm{C}$ for 4 min and 5 cycles of $95^{\circ} \mathrm{C}$ for $30 \mathrm{~s}, 52^{\circ} \mathrm{C}$ for $45 \mathrm{~s}, 72^{\circ} \mathrm{C}$ for $1 \mathrm{~min} 30 \mathrm{~s}$ and a final extension of $72^{\circ} \mathrm{C}$ for $7 \mathrm{~min}$. PCR reactions were purified using High pure PCR purification kit (Roche). DNA was quantified using a spectrophotometer (Nanodrop), with $250 \mathrm{ng}$ sent for sequencing. MassRuler ${ }^{\mathrm{TM}}$ Express LR Forward DNA Ladder, 
ready-to-use use to quantify the about of PCR product present in the sample. GeneRuler $^{\mathrm{TM}} 1 \mathrm{~kb}$ DNA ladder

Archaeal Pyrosequencing

A two-step pyrosequencing approach was used (as used in bacterial pyrosequencing protocol). First round primers ARC344f-mod and Arch958R-mod targeted the V4 and V5 regions of the 16S rDNA archaeal gene. This product was used as a template for the second PCR reaction. Barcodes for the primers were picked from literature (Hamady et al. 2008).

$\underline{\text { Sequence Analysis }}$

PCR product concentration was measured using a fluorimeter as per manufactures instructions; ( $1 \mu 1$ of PCR $149 \mu 1$ of 1 XTAE buffer and $50 \mu 11 \mathrm{x}$ dye and incubated in the dark for $5 \mathrm{mins})$. The amplicons were pooled and sequenced at a DNA Sequencing Facility, (Department of Biochemistry, University of Cambridge, UK) by using a One-way read strategy from the reverse primer, Titanium chemistry on a 454 GS Junior Devise (Roche). Quantitative sequence analysis was carried out in QIIME pipeline v 1.7 (Caporaso et al. 2010b). Sequences were filtered to exclude reads shorter than 200bp and with mismatches in the barcode or primer. Quality filter was made with USEARCH (Edgar 2010) and UCHIME (Edgar et al. 2011) to exclude chimeras, singletons were removed as well. USEARCH was also used to pick Operational Taxonomic Units (OTUs) based on 97\% similarity with a de novo method. Alignment was done using PyNAST (Caporaso et al. 2010a).

Taxonomy was assigned against the Greengenes reference database (DeSantis et al. 2006) (released on May 2013) by using RDP classifier v2.2 (McDonald et al. 2012) (ribosomal database project) (Wang et al. 2007) with a confidence limit of 0.8 . Commands included in QIIME were used to obtain rarefaction curves and to calculate 
alpha diversity metrics, whereas Unifrac (Lozupone and Knight 2005) was used to calculate beta diversity. For visual representation minor groups of less than $1 \%$ abundance were grouped. Raw sequences were archived in the European Nucleotide Archive (ENA) under the study accession number; PRJEB6020. Direct link to the data can be found at http://www.ebi.ac.uk/ena/data/view/PRJEB6020

\section{RESULTS}

\section{Induced Polarization}

Data analysis of IP data discarded readings with larger repetition error (above 4$5 \%$ ). These values were mostly from the electrodes downhole. To work with uniform data sets, in terms of electrode distribution and associated model sensitivity, only surface IP data acquired with wenner array in May and July 2012 and April 2013 entered further analysis. Since only surface data were used, the depth of IP investigation (of about $6 \mathrm{~m}$ ) was not enough to span the depth levels in which FGP reservoirs were identified in sampling wells. As shown in Figure 5 levels to $6 \mathrm{~m}$ depth identify minor variations in resistivity, chargeability, and normalized chargeability sections. These sections were used to estimate the range for the partition parameter $f$, according its definition in equation 9. Figure 6 shows the processing scheme to determine this parameter, by illustrating it with data set of July 2012. Estimates for $f$ in Figure 6 were computed pixel-by-pixel by algebraic operations involving the resistivity and chargeability sections according equation 7. Bulk conductivity was evaluated from equation 9 and used to evaluate parameter $f$ according equation 10 . The procedure illustrated in Figure 6 was replicated for data sets of May and July 2012 and April 2013. The integration of results shows that parameter $f$ varies within 0.7 and 0.9 (Figure 7). For such a range, the square root of ratios as prescribed in equation 12 assume values very close to 1 , meaning that for the conditions found in the test site, simple Archie's 
law, not taking into account surface conductivity, can representative of saturation change inferred from the ratio of resistivity values. Results are then practically the same when making $f=1$.

$\underline{\text { Saturation change mapping }}$

Figure 8 shows resistivity sections and resistivity ratios with respect to the averaged resistivity model (AVG). Unitary ratio contour line $\left(R_{i, k}=1\right)$ delimits "up" domains with $R_{i, k}>1$ and "down"domains with $R_{i, k}<1$. Up domains are compatible with increasing water saturation (with respect to AVG background model) and down domains with increasing of FGP content. Changes in MAR-2012 and APR-2013 are then compatible with downward groundwater flow suggesting connected pathways crossing main interfaces recognized from combined resistivity and core data. The time shot in MAY-2012 can be regarded as capturing minor accommodation or fluctuations of water and gas phases with respect to an averaged background. No time-shot captured a major event connecting the shallowFPG1 and deeper FGP2 reservoirs, suggesting that the deeper FGP2 reservoir is well sealed, a hypotheses corroborated by rather uniform pressure of $98.0 \mp 0.2 \mathrm{kPa}$ measured since 2011 . This over pressure is about 4 to $5 \%$ above mean atmosphere. This gradient allows FGP flushing at a rate of $4.5-5.0 \mathrm{dm}^{3} \mathrm{~min}^{-1}$ when the well is kept open to the atmosphere. This rate of escape, however, is also conditioned by the well construction, does not meaning that a natural event of ebullition would take place at this rate. The change observed in JUN-2013 suggests a temporary gas pathway connecting the deeper confined reservoir (FGP2) directly to the vadose zone, with no clear transition to the shallow gas reservoir (FGP1).

\section{$\underline{\text { Fermentative Bacteria }}$}

Sample 1 (Figure 9) was collected at the depth of $2.5 \mathrm{~m}$ (anthropogenic deposits) and sample 2 was taken from the same borehole at $8.4 \mathrm{~m}$ depth, sample 3 was collected 
from another borehole also at $8.4 \mathrm{~m}$ depth (geogenic sediment layer). The bacterial taxonomic profile for sample 1 showed the least amount of diversity at the genus level with OD1 dominating (78.30\%), minor genus $(9.80 \%)$, OP11 (6.70\%). For sample 2 OD1 also dominated (37.90\%) other bacteria are more abundant (33.70\%), minor genus (14.80\%), along with OP11 (10.0\%) and OP3 (3.60\%) also present. Sample 3 is the most diverse sample, with OD1 still dominating (54.60\%), minor genus $(19.10 \%)$, OP11 (13.0\%), OP3 (5.30\%), Geothrix (2.70\%), Syntrophus (2.40\%), Desulfosporosinus (1.0\%), and unclassified bacterial sequences are present in all the samples (Figure 9). The candidate division OD1 is present in all the samples and the distribution does not seem to follow an ecological pattern dominating in both geogenic and anthropogenic deposits. OD1 has mainly been found in anoxic zones (Elshahed et al. 2005) and having been identified in an acetate amended aquifer it was suggested to be fermentative (Wrighton et al. 2012). Samples 2 and 3 are the locations at which most methane production is likely to be occurring and it has been suggested OD1 can possibly anaerobically oxidise methane (Peura et al. 2012). The results show OD1 to be found in areas with oxygen present, with varying amounts of acetate and other contaminants and not limited to areas of methane production. From the wide spread distribution in varied environments it appears OD1 is ubiquitous. It most likely has a vast repertoire of metabolic capabilities and in such as heterogeneous environments it could be carrying out a number of processes. OP11 like OD1 has also been associated with an obligatory fermentation lifestyle (Wrighton et al. 2014) Syntrophus grows via syntrophic association with hydrogen utilising microorganisms and oxidizing substrate incompletely to acetate (Ragauskas et al. 2014). Geothrix genus are capable of reducing Fe(III) (Lovley 2008) and Desulfosporosinusis a sulphate reducer which may inhibit methane production (Pester et al. 2010). 


\section{Methanogenic Archea}

Archaeal taxonomic profile shows phylum level diversity in all the samples is dominated by Euryarchaeota and Crenarchaeota. Parvarchaeota and other phylum are also present but in much lower relative abundance. At the Genus level Methanosaeta is an acetoclastic methanogen and is most dominant methanogen in all the samples (Figure 9) the abundance increases with depth as the environment becomes more anaerobic. Methane producing archaea are naturally found in the sediments and Methanosaeta are ubiquitous in the environment with a high affinity for acetate (Lee et al. 2014). Acetotrophic methanogens are obligate anaerobic which convert acetate to methane and carbon dioxide. It is likely that the production of methane is as a result of the indigenous microbial populations and the presence of large quantities of organic matter within the subsurface. Interestingly, it has recently been reported that some Methanosaeta species are also capable of direct interspecies electron transfer (DIET) with some Geobacter species for the reduction of carbon dioxide to methane (Rotaru et al. 2014). Methanosaeta is believed to be one of the principal methane produces on the planet (Smith and Ingram-Smith 2007) and the ability to accept electrons from other species or even abiotic sources may provide an additional advantage. The distribution of methanogens correlated with the methane pockets and higher levels of acetate. Methane produced at depth by these microorganisms could escape to the atmosphere or be oxidised by methane oxidising bacteria such as OD1 or other archaea.

\section{DISCUSSION}

An intriguing result from our study is the invariance of the subsurface resistivity over a time-scale of months. The procedure to jointly interpret resistivity and IP in terms of saturation ratios allowed recognition of processes that were not perceptible by the simple inspection of resistivity or chargeability sections. The invariance in 
resistivity sections is particularly intriguing when considering that the deeper FGP2 reservoir is consistently overpressured with respect to the atmosphere pressure by about 3.9-4.9 $\mathrm{kPa}$. The saturation-ratio analyses captured only a single time-shot with abrupt variation, showing that variations in the deeper over pressured FGP2 reservoir can be temporarily directly connected to shallow layers in the vadose zone. This is an important result since it high lights risks associated with abrupt releases of biogas, possibly as ebullition, and is related to the conditions of the deeper reservoir, not necessarily affected by conditions of the shallow FGP1 biogas reservoir. This shallow FGP1 reservoir, with pressure equilibrated to the atmosphere, may be involved with events of smaller escapes to the atmosphere, possibly in response to fluctuations in atmospheric conditions (pressure, wind) or water seepage. Resistivity variations in the layer with dredged sediments are compatible with "water in $(R>1)$ " events, in rainwater seepage. Temperature variations however can compromise the saturation analysis in the very shallow (1-2 m) levels. What was not previously recognized is that such events of recharge seem to pass through the anthropogenic deposits leaching its contents to deeper levels. No event of "gas in $(R>1)$ " was captured at ground surface. This slow release of biogas from the shallow FGP1 reservoir with large quantities of the OD1 genus which may be able to anaerobically oxidise methane, coupled with surface ingression of aerobic rainwater alongside aerobic atmospheric oxygen may help attenuate the overall emission of methane to the surface.

The lack of diversity amongst both bacterial and archeal communities across anthropogenic and geogenic deposits is surprising. The leaching of groundwater through anthropogenic deposits to geogenic deposits at depth coupled with the temporary upward migration of biogas in reservoirs may explain why the distribution of bacterial fermenters and acetoclastic methanogens is similar across the sample locations with 
diversity slightly increasing with depth. This rise and fall of the water table may also promote pathways for biogas to travel and be trapped, as well as for the downward leaching of contaminants (Mendonça et al., 2015). This seasonal vertical mobility of groundwater (downwards) and biogas (upwards) creates a widespread stable and homogenous community of fermenting bacteria and biogas producing acetoclastic archea, the effects of which were monitored by near surface geophysical techniques.

\section{CONCLUSIONS}

The procedure to interpret resistivity and IP provided a background to apply the Archie's law to estimate changes in water saturation from resistivity sections at a test site with trapped FGP (methane and carbon dioxide, mainly). For this particular test site, the contribution of surface conductivity, despite expressive (up to $20-30 \%$ of bulk conductivity) does not prevented reliable estimates for relative changes in water saturation. Important results to site characterization and recognizing of groundwater and FGP flow paths were obtained with the saturation-ration analysis. These results suggest possibility of temporary connections between the confined deep FGP2 reservoir directly with the vadose zone. This is a potential scenario for an abrupt escape of biogas to the atmosphere from a deeper geogenic source $(\sim 8 \mathrm{~m})$, possibly resembling events of ebullition observed in inland water bodies, and wetlands. A relatively homogenous subsurface microbial community appears to be present with bacterial fermenters such as the OD1 genus and gas producing acetoclastic methanogens such as Methanosaeta dominating all subsurface samples across anthropogenic and geogenic deposits. This lack of diversity may be due to physical subsurface characteristics monitored by resistivity and IP, the downward vertical transfer of recharging groundwater and periodic upward migration of biogas homogenizing the microbial communities. From the data gathered to date it is not possible to forecast possible periodicity for these 
events or if direct escape to the vadose zone (as captured in JUN-2013) is the predominant way of gas release. The conceptual model presented does require that monitoring of soil biogas should occur across a variety of depths to account all types of emission scenario.

\section{ACKNOWLEDGEMENTS}

This work was partly funded by CNPq 301746/2010-9 and FAPESP 2013/22912; 2013/08754-4. B McPolin was funded by the Department of Employment and Learning (Northern Ireland) and travel to USP was through a Santander student bursary.

\section{REFERENCES}

AGIUSA, 2009, Instruction manual for EarthImager 2D version 2.4.0 resistivity and IP inversion software. Advanced Geosciences Inc, companion CD.

Archie, G.E., 1942. The electrical resistivity log as an aid in determining some reservoir characteristics, Trans. Am. Inst. Min. Metall. Eng., 146, 54-62.

Bastviken, D., L. J. Tranvik, J. A. Downing, P. M. Crill, A. Enrich-Prast, 2011,Freshwater methane emissions offset the continental carbon sink: Science, 331, 50. doi:10.1126/science.1196808/

Bergmann, P., C. Schmidt-Hattenberger, D. Kiessling, C. Rücker, T. Labitzke, J. Henninges, G. Baumann, H. Schütt, 2012, Surface-downhole electrical resistivity tomography applied to monitoring of $\mathrm{CO} 2$ storage at Ketzin, Germany: Geophysics, 77, B253-B267. doi10.1190/GEO2011-0515.1 
Berry D, Mahfoudh K Ben, Wagner M, Loy A., 2011, Barcoded primers used in multiplex amplicon pyrosequencing bias amplification. Appl Environ Microbiol.: 77(21),7846-9. doi:10.1128/AEM.05220-11

Caporaso JG, Bittinger K, Bushman FD, DeSantis TZ, Andersen GL, Knight R. PyNAST: a flexible tool for aligning sequences to a template alignment, 2010a, Bioinformatics: 26(2):266-7. doi:10.1093/bioinformatics/btp636

Caporaso JG, Kuczynski J, Stombaugh J, Bittinger K, Bushman FD, Costello EK, et al., 2010b, QIIME allows analysis of high-throughput community sequencing data, Nature Methods, 7(5):335-6. doi:10.1038/nmeth.f.303

Chen, X., andL. Slater, 2015, Gas bubble transport and emissions for shallow peat from a northern peatland: The role of pressure changes and peat structure:Water Resour. Res.,51,151-168, doi:10.1002/2014WR016268.

Comas, X., L. Slater, and A. Reeve, 2008, Seasonal geophysical monitoring of biogenic gases in a northern peatland: Implications for temporal and spatial variability in free phase gas production rates, J. Geophys. Res., 113, G01012, doi:10.1029/2007JG000575.

Comas, X., L. Slater, and A. S. Reeve, 2011, Atmospheric pressure drives changes in the vertical distribution of biogenic free-phase gas in a northern peatland, J. Geophys. Res., 116, G04014, doi:10.1029/2011JG001701.

Christensen, T.R, 2010, Wetlands, in Methane and climate change, Ed. D. Reay, P. Smith,and A. Van Amstel. Earthscan Ltd. ISBN 978-1-84407-823-3 
Daniel R., 2005, The metagenomics of soil, Nat Rev Microbiol, 3(6):470-8. doi:10.1038/nrmicro1160

Danielsen, B. E., T. Dahlin, 2010, Numerical modelling of resolution and sensitivity of ERT in horizontal boreholes: Journal of Applied Geophysics, 70, 245-254. doi:10.1016/j.jappgeo.2010.01.005.

deLima, O. A. L. and M. M. Sharma, 1992, A generalized Maxwell Wagner theory for membrane polarization in shaly sands: Geophysics, 57, 431-440. doi: $10.1190 / 1.1443257$

deSantis TZ, Hugenholtz P, Larsen N, Rojas M, Brodie EL, Keller K, et al., 2006, Greengenes, a chimera-checked 16S rRNA gene database and workbench compatible with ARB: Appl Environ Microbiol, 72(7):5069-72. doi: 10.1128/AEM.03006-05

Dojka MA, Hugenholtz P, Haack SK, Pace NR. Microbial diversity in a hydrocarbonand chlorinated-solvent-contaminated aquifer undergoing intrinsic bioremediation, 1998, Appl Envir Microbiol; 64(10), 3869-77.

Edgar RC., 2010, Search and clustering orders of magnitude faster than BLAST. Bioinformatics; 26(19):2460-1. doi: 10.1093/bioinformatics/btq461

Edgar RC, Haas BJ, Clemente JC, Quince C, Knight R., 2011, UCHIME improves sensitivity and speed of chimera detection, Bioinformatics, 27(16), 2194-200. doi:10.1093/bioinformatics/btr381

Elshahed MS, Najar FZ, Aycock M, Qu C, Roe BA, Krumholz LR, 2005, Metagenomic analysis of the microbial community at Zodletone Spring (Oklahoma): insights into the 
genome of a member of the novel candidate division OD1: Appl Environ Microbiol.,71(11):7598-602. doi: 10.1128/AEM.71.11.7598-7602.2005

Farquharson, C. G., 2008, Constructing piecewise-constant models in multidimensional minimum-structure inversions: Geophysics, 73, K1-K9. doi: 10.1190/1.2816650

Ferguson AS, Huang WE, Lawson KA, Doherty R, Gibert O, Dickson KW, 2007, Microbial analysis of soil and groundwater from a gasworks site and comparison with a sequenced biological reactive barrier remediation process: J Appl Microbiol., 102:1227-38. doi:10.1111/j.1365-2672.2007.03398.x

Florsch, N, A. Revil and C. Camerlynck, 2014. Inversion of generalized relaxation time distributions with optimized damping parameter: Journal of Applied Geophysics (109): 119-132. doi:10.1016/j.jappgeo.2014.07.013.

Hamady M, Walker JJ, Harris JK, Gold NJ, Knight R., 2008, Error-correcting barcoded primers for pyrosequencing hundreds of samples in multiplex: Nature Methods 5(3):2007-9. doi:10.1038/nmeth. 118

Jougnot D., A., Ghorbani, A. Revil, P. Leroy and P. Cosenza,2010, Spectral Induced Polarization of partially saturated clay-rocks: A mechanistic approach: Geophysics Journal International, 180, 210-224. doi:10.1111/j.1365-246X.2009.04426.x

Joyce, J. and Jewell, P.W., 2003, Physical Controls on Methane Ebullition from Reservoirs and Lakes: Environmental \& Engineering Geoscience, 9, 167-178, doi:10.2113/9.2.167 
Karaoulis, M., A. Revil, P. Tsourlos, D.D. Werkema, B. J. Minsley, 2013, IP4DI: A software for time-lapse 2D/3D DC-resistivity and induced polarization tomography, Computers \& Geosciences, 54, 164-170. doi:10.1016/j.cageo.2013.01.008

Kemna, A., A. Binley, G. Cassiani, E. Niederleithinger, A. Revil, L. Slater, K. Williams, A.F., Orozco, F.H. Haegel, A., Hördt, S., Kruschwitz, V., Leroux, K., Titov and E. Zimmermann, 2012, An overview of the spectral induced polarization method for near-surface applications: Near Surface Geophysics, 10, 453-468. doi:10.3997/18730604.2012027.

Kettridge, N., A. Binley, S. M. Green, and A. J. Baird, 2011, Ebullition events monitored from northern peatlands using electrical imaging, J. Geophys. Res., 116, G04004.doi:10.1029/2010JG001561.

Lee J, Hwang B, Koo T, Shin SG, Kim W, Hwang S. Temporal variation in methanogen communities of four different full-scale anaerobic digesters treating food wasterecycling wastewater, 2014, Bioresour Technol., 168, 59-63. doi:10.1016/j.biortech.2014.03.161

Li Y, Saxena D, Chen Z, Liu G, Abrams WR, Phelan JA, et al. HIV infection and microbial diversity in saliva, 2014, J Clin Microbiol: 52(5), 140011.doi:10.1128/JCM.02954-13

Li, Y. and D. Oldenburg, 2000, 3-D inversion of induced polarization data: Geophysics, 65, 1931-1945. doi:10.1190/1.1444877 
Liu Y, Whitman WB. Metabolic, phylogenetic, and ecological diversity of the methanogenic archaea, 2008, Ann N Y Acad Sci: 1125, 171-89. doi:10.1196/annals.1419.019.

Leroy P. and A. Revil, 2009, A mechanistic model for the spectral induced polarization of clay materials. Journal of Geophysical Research 114., B10202. doi:10.1029/2008JB006114

Loke, M. H., I. Acworth, T.Dahlin, 2003, A comparison of smooth and blocky inversion methods in 2D electrical imaging surveys: Exploration Geophysics, 34(3), 182-187. doi:10.1071/EG03182

Loke, M.H., J.E. Chambers, D.F. Rucker, O. Kuras, P.B. Wilkinson, 2013, Recent developments in the direct-current geoelectrical imaging method: Journal of Applied Geophysics, 95, 135-156. doi:10.1016/j.jappgeo.2013.02.017

Lovley, D.R., 2008, Extracellular electron transfer: wires, capacitors, iron lungs, and more: Geobiology, 6, 225-31. doi: 10.1111/j.1472-4669.2008.00148.x

Lozupone C, Knight R., 2005, UniFrac: a new phylogenetic method for comparing microbial communities: Appl Environ Microbiol., 71, 8228-35. doi: 10.1128/AEM.71.12.8228-8235.2005

McDonald D, Price MN, Goodrich J, Nawrocki EP, DeSantis TZ, Probst A, et al., 2012, An improved Greengenes taxonomy with explicit ranks for ecological and evolutionary analyses of bacteria and archaea: ISME J., 6, 610-8. doi:10.1038/ismej.2011.139 
Mendonça, C.A., R. Doherty, A. Fornaro, E. L. Abreu, G. C. Novaes, S. Jr. S. Fachin, M. A. La-Scalea, 2015, Integrated earth resistivity tomography (ERT) and multilevel sampling gas: a tool to map geogenic and anthropogenic methane accumulation on brownfield sites: Environ Earth Science. doi:10.1007/s12665-015-4111-6

Musgrave, H., and A. Binley, 2011, Revealing the temporal dynamics of subsurface temperature in a wetland using time-lapse geophysics: Journal of Hydrology, 396, 258266. doi:10.1016/j.jhydrol.2010.11.008

Oldenburg, D. W. and Y. Li, 1994, Inversion of induced polarization data: Geophysics, 59, 1327-1341. doi:10.1190/1.1443692

Orcutt B.N., Sylvan J.B., Knab N.J., Edwards K.J., 2011, Microbial ecology of the dark ocean above, at, and below the seafloor. Microbiol Mol Biol Rev, 75, 361-422. doi:10.1128/MMBR.00039-10

Parsekian, A. D., X. Comas, L. Slater, and P. H. Glaser, 2011, Geophysical evidence for the lateral distribution of free phase gas at the peat basin scale in a large northern peatland, J. Geophys. Res., 116, G03008, doi:10.1029/2010JG001543.

Pester M, Bittner N, Deevong P, Wagner M, Loy A., 2010, A “rare biosphere" microorganism contributes to sulfate reduction in a peatland: ISME J. 4, 1591-602. doi:10.1038/ismej.2010.75

Peura S, Eiler A, Bertilsson S, Nykänen H, Tiirola M, Jones RI. Distinct and diverse anaerobic bacterial communities in boreal lakes dominated by candidate division OD1, 2012, ISME J, 6, 1640-52. doi:10.1038/ismej.2012.21 
Pidlisecky, A., E. Haber, R. Knight, 2007; RESINVM3D: A 3D resistivity inversion package, Geophysics,72, H1-H10. doi:10.1190/1.2402499

Pidlisecky, A., R. Knight, E. Haber, 2006, Cone-based electrical resistivity tomography: Geophysics, 71, G157-G167. Doi10.1190/1.2213205.

Power, C., J. I. Gerhard, P. Tsourlos, P. Soupios, K. Simyrdanis, M. Karaoulis, 2015, Improved time-lapse electrical resistivity tomography monitoring of dense non-aqueous phase liquids with surface-to-horizontal borehole arrays: Journal of Applied Geophysics, 112, 1-13. doi:10.1016/j.jappgeo.2014.10.022.

Ragauskas AJ, Rabaey K, Harms H, Junca H, Gieg LM, Fowler SJ, et al., 2014, Syntrophic biodegradation of hydrocarbon contaminants: Curr Opin Biotechnol., 27, 21-29. doi:10.1016/j.copbio.2013.09.002

Revil A., M. Karaoulis, T. Johnson, A. Kemna, 2012, Review: Some low-frequency electrical methods for subsurface characterization and monitoring in hydrogeology. Hydrogeol Journal. doi:10.1007/s10040-011-0819-x

Revil, A. and N. Florsch, 2010, Determination of permeability from spectral induced polarization in granular media: Geophysical Journal International, 181, 1480-1498. doi:10.1111/j.1365-246X.2010.04573.X

Rotaru A-E, Shrestha PM, Liu F, Shrestha M, Shrestha D, Embree M, et al., 2014, A new model for electron flow during anaerobic digestion: direct interspecies electron transfer to Methanosaeta for the reduction of carbon dioxide to methane: Energy Environ Sci, 7, 408-15. doi:10.1039/C3EE42189A 
Schütze, C., P. Dietrich, U. Sauer, 2013, Diagnostic monitoring to identify preferential near-surface structures for $\mathrm{CO} 2$ degassing into the atmosphere: Tools for investigations at different spatial scales validated at a natural analogue site: International Journal of Greenhouse Gas Control, 18, 285-295. doi:10.1016/j.ijggc.2013.07.006

Smith KS, Ingram-Smith C., 2007, Methanosaeta, the forgotten methanogen?: Trends Microbiol, 15, 150-155. doi:10.1016/j.tim.2007.02.002

Slater, Lee, X. Comas, D. Ntarlagiannis, M.R. Moulik, 2007, Resistivity-based monitoring of biogenic gases in peat soils: Water Resources Research, 43, W10430, doi:10.1029/2007WR006090.

Stamp, I., A. J. Baird, and C. M. Heppell, 2013, The importance of ebullition as a mechanism of methane (CH4) loss to the atmosphere in a northern peatland, Geophys. Res. Lett., 40, 2087-2090, doi:10.1002/grl.50501.

Vinegar, H. J. and M. H. Waxman, 1984, Induced polarization of shaly sands, 49, 12671287. doi:10.1190/1.1441755.

Yu, Z., L. D. Slater, K. V. R. Schäfer, A. S. Reeve, R. K. Varner, 2014, Dynamics of methane ebullition from a peat monolith revealed from a dynamic flux chamber system: J. Geophys. Res. Biogeosci., 119, 1789-1806, doi:10.1002/2014JG002654.

Walter, K.M., S.A. Zimov, J.P. Chanton, D. Verbyla, F.S. Chapin, 2006, Methane bubbling from Siberian thaw lakes as a positive feedback to climate warming, Nature, 443, 71-75. doi:10.1038/nature 05040 
Wang Q, Garrity GM, Tiedje JM, Cole JR., 2007, Naive Bayesian classifier for rapid assignment of rRNA sequences into the new bacterial taxonomy: Appl Environ Microbiol., 73, 5261-5267. doi:10.1128/AEM.00062-07

Weiland P., 2010, Biogas production: Current state and perspectives: Appl. Microbiol. Biotechnol. 85, 849-860. doi:10.1007/s00253-009-2246-7

Wrighton KC, Castelle CJ, Wilkins MJ, Hug L a, Sharon I, Thomas BC, et al., 2014, Metabolic interdependencies between phylogenetically novel fermenters and respiratory organisms in an unconfined aquifer. ISME J, 8, 1452-1463. doi:10.1038/ismej.2013.249

Wrighton KC, Thomas BC, Sharon I, Miller CS, Castelle CJ, VerBerkmoes NC, et al., 2012, Fermentation, hydrogen, and sulfur metabolism in multiple uncultivated bacterial phyla. Science, 337, 1661-1665. doi:10.1126/science.1224041

Worthington, P. F., 2011, Quality-assured evaluation of freshwater-bearing hydrocarbon reservoirs: Journal of Petroleum Science and Engineering, 78,542-551. doi:10.1016/j.petrol.2011.06.008 


\section{FIGURE CAPTIONS}

Figure 1- FPG (free-phase gas) reservoirs and background resistivity; a) Conceptual model from continuous core samples, sediment analysis (grain size, organic carbon content), water and gas sampling from multi-level monitoring wells, each one with 15 sampling ports $0.6 \mathrm{~m}$ apart; b) Resistivity section acquired in day 24 after the installation of wells; c) gas composition from sampling ports with gas; the shallow level corresponding to the vadose zone; reservoir FGP1 has pressure equilibrated to the atmosphere; reservoir FGP2 has pressure 0.4 to $0.5 \mathrm{kPa}$ above the atmospheric pressure.

Figure 2- Raw apparent resistivity values acquired in 2012 and 2013. Each survey with 460 data points from merging wenner and dipole-dipole arrays, with 28 electrodes $2 \mathrm{~m}$ spaced at the ground surface and 5 electrodes (permanently installed) downhole.

Figure 3- Misfit (L-2 norm) in fitting measured data sets as a function of smoothness parameter. The choice of a common parameter (100 in this case) intended to apply the same degree of smoothness when inverting each data set. For values greater than 100 , smoothness become arbitrarily higher, not honouring data fitting.

Figure 4- Data fitting provided by resistivity models from data inversion of resistivity surveys carried out in 2012 and 2013.

Figure 5- Inversion results of resistivity and IP data for 2012 and 2013 surveys employing Wenner array with 28 electrodes at the ground surface; a) inverted resistivity model; b) chargeability model; c) normalized chargeability model. 
Figure 6- Illustration of the processing flow chart to obtain the parameter of conductivity partition, f, from imputing conductivity (a) and chargeability (b) sections obtained from data inversion, evaluation of normalized chargeability (c) and bulk conductivity (d) that enter in the evaluation of partition parameter (e).

Figure 7- Conductivity partition parameter, $\mathrm{f}$, as a function of medium resistivity. Values between 0.7 and 0.9 suggest that bulk conductivity is the main contributor in the electrical conductivity, surface conductivity accounting with $10 \%$ to $30 \%$ of total conductivity.

Figure 8-Resistivity sections (a) and resistivity ratios with respect to averaged (AVG) model (b). Unitary ratio contour line (white) delimits domains where $R_{c}>1$ (water saturation increases) and $\mathrm{R}_{\mathrm{c}}<1$ (water saturation diminishes) with respect to AVG background model. Inset in (c) shows differences between assuming $f=1(R b)$ or according empirical formula $\mathrm{f}=-0.06473 * \log _{10}(\rho)+0.94037(\mathrm{Rc})$.

Figure 9- Bacterial and Archeal genus level taxonomic profile of suspended sediment in groundwater from different depths. Sample 1) was taken from depth of $2.5 \mathrm{~m}$ (waste deposits) and samples 2) and 3) are both taken from a depth of $8.4 \mathrm{~m}$ (fluvial sediment layer). 
a)
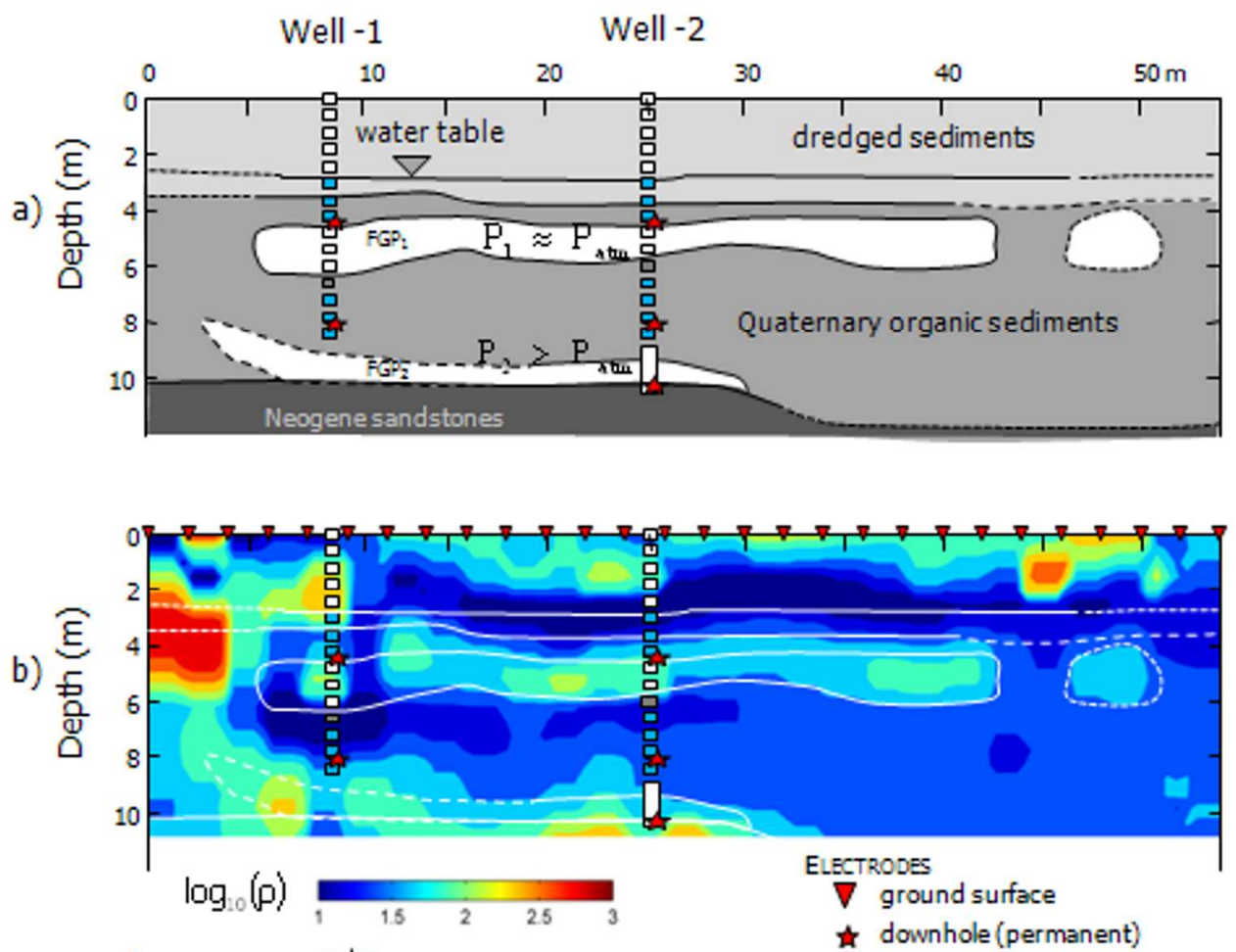

c)

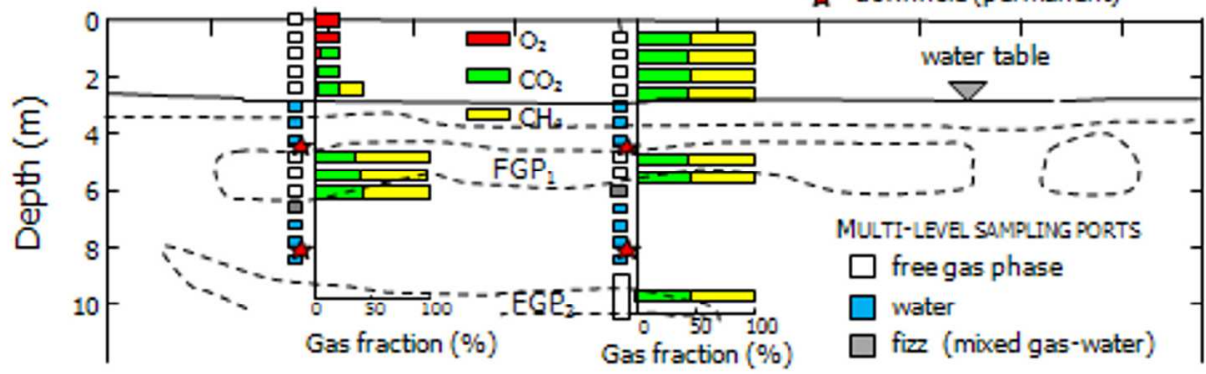

1. FPG (free-phase gas) reservoirs and background resistivity; a) Conceptual model from continuous core samples, sediment analysis (grain size, organic carbon content), water and gas sampling from multi-level monitoring wells, each one with 15 sampling ports $0.6 \mathrm{~m}$ apart; b) Resistivity section acquired in day 24 after the installation of wells; c) gas composition from sampling ports with gas; the shallow level corresponding to the vadose zone; reservoir FGP1 has pressure equilibrated to the atmosphere; reservoir FGP2 has pressure 0.4 to $0.5 \mathrm{kPa}$ above the atmospheric pressure. $200 \times 223 \mathrm{~mm}(300 \times 300$ DPI $)$ 


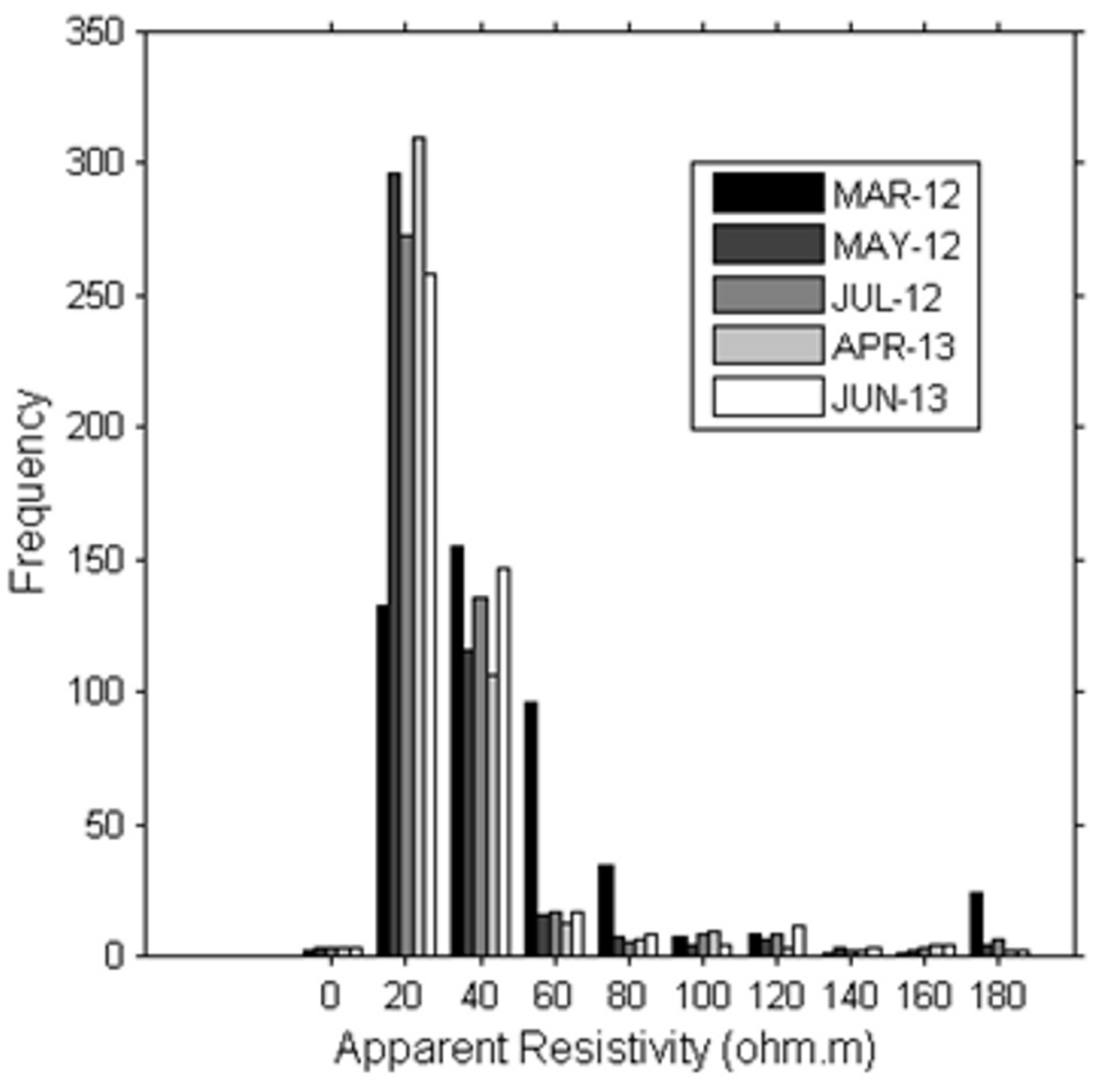

2. Raw apparent resistivity values acquired in 2012 and 2013 . Each survey with 460 data points from merging wenner and dipole-dipole arrays, with 28 electrodes $2 \mathrm{~m}$ spaced at the ground surface and 5 electrodes (permanently installed) downhole. $149 \times 143 \mathrm{~mm}(300 \times 300 \mathrm{DPI})$ 


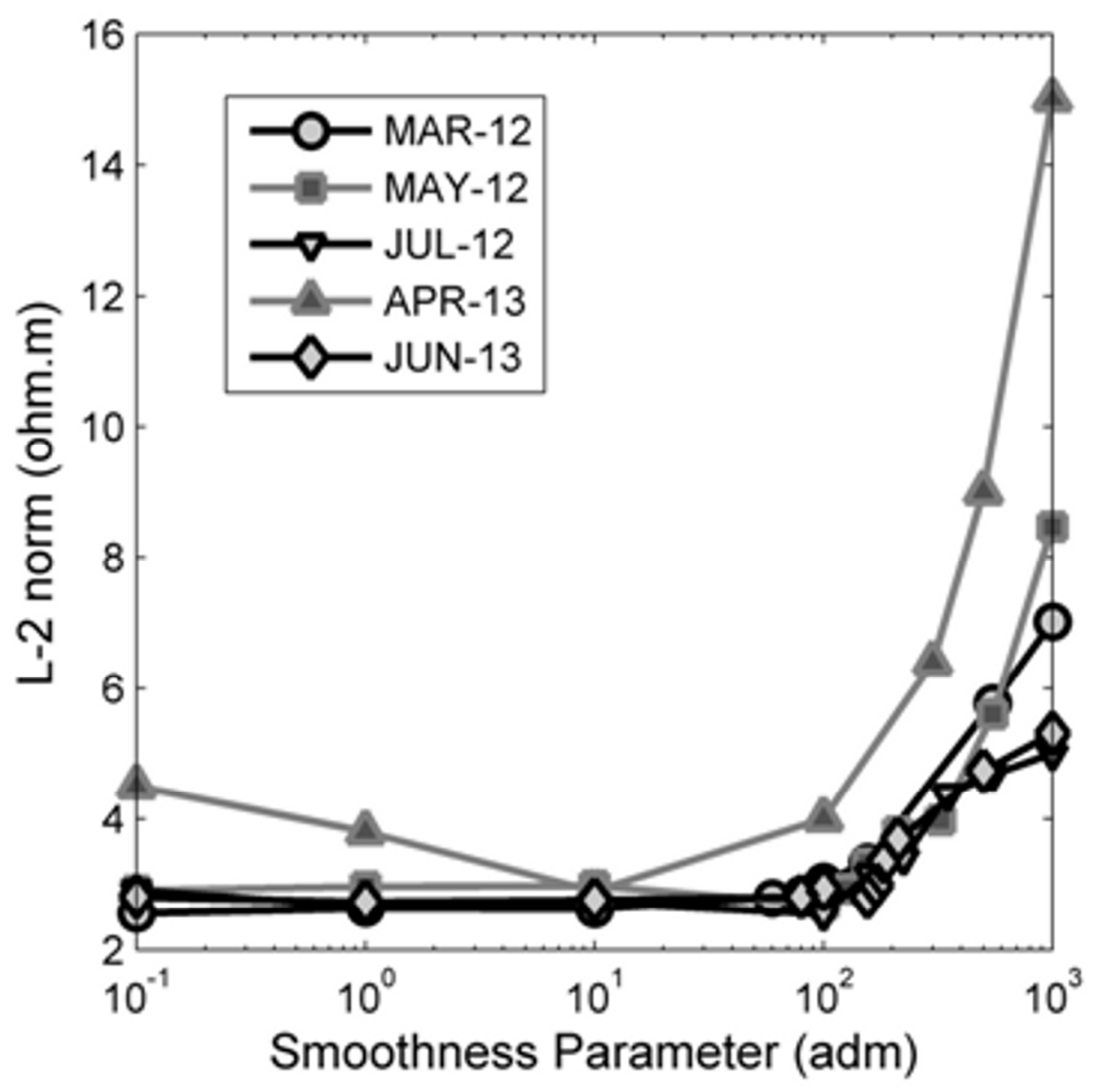

3. Misfit (L-2 norm) in fitting measured data sets as a function of smoothness parameter. The choice of a common parameter (100 in this case) intended to apply the same degree of smoothness when inverting each data set. For values greater than 100 , smoothness become arbitrarily higher, not honouring data fitting.

$150 \times 151 \mathrm{~mm}(300 \times 300 \mathrm{DPI})$ 


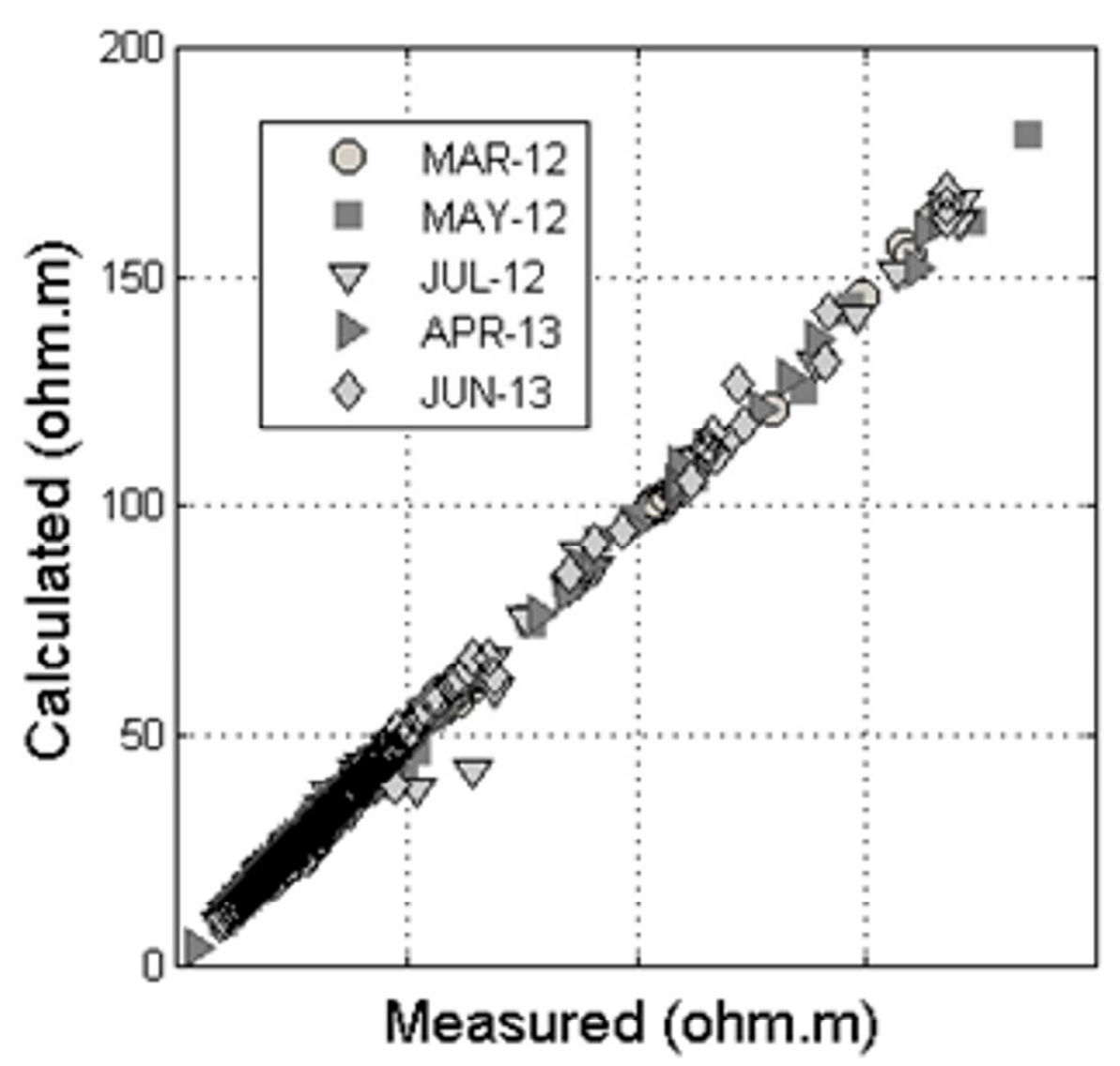

4. Data fitting provided by resistivity models from data inversion of resistivity surveys carried out in 2012 and 2013. $150 \times 145 \mathrm{~mm}(300 \times 300$ DPI $)$ 


\section{Page 41 of 45}

5. Inversion results of resistivity and IP data for 2012 and 2013 surveys employing Wenner array with 28 electrodes at the ground surface; a) inverted resistivity model; b) chargeability model; c) normalized chargeability model. $150 \times 55 \mathrm{~mm}(300 \times 300$ DPI $)$ 
6. Illustration of the processing flow chart to obtain the parameter of conductivity partition, f, from imputing conductivity (a) and chargeability (b) sections obtained from data inversion, evaluation of normalized chargeability (c) and bulk conductivity (d) that enter in the evaluation of partition parameter (e). $180 \times 128 \mathrm{~mm}(300 \times 300$ DPI $)$ 


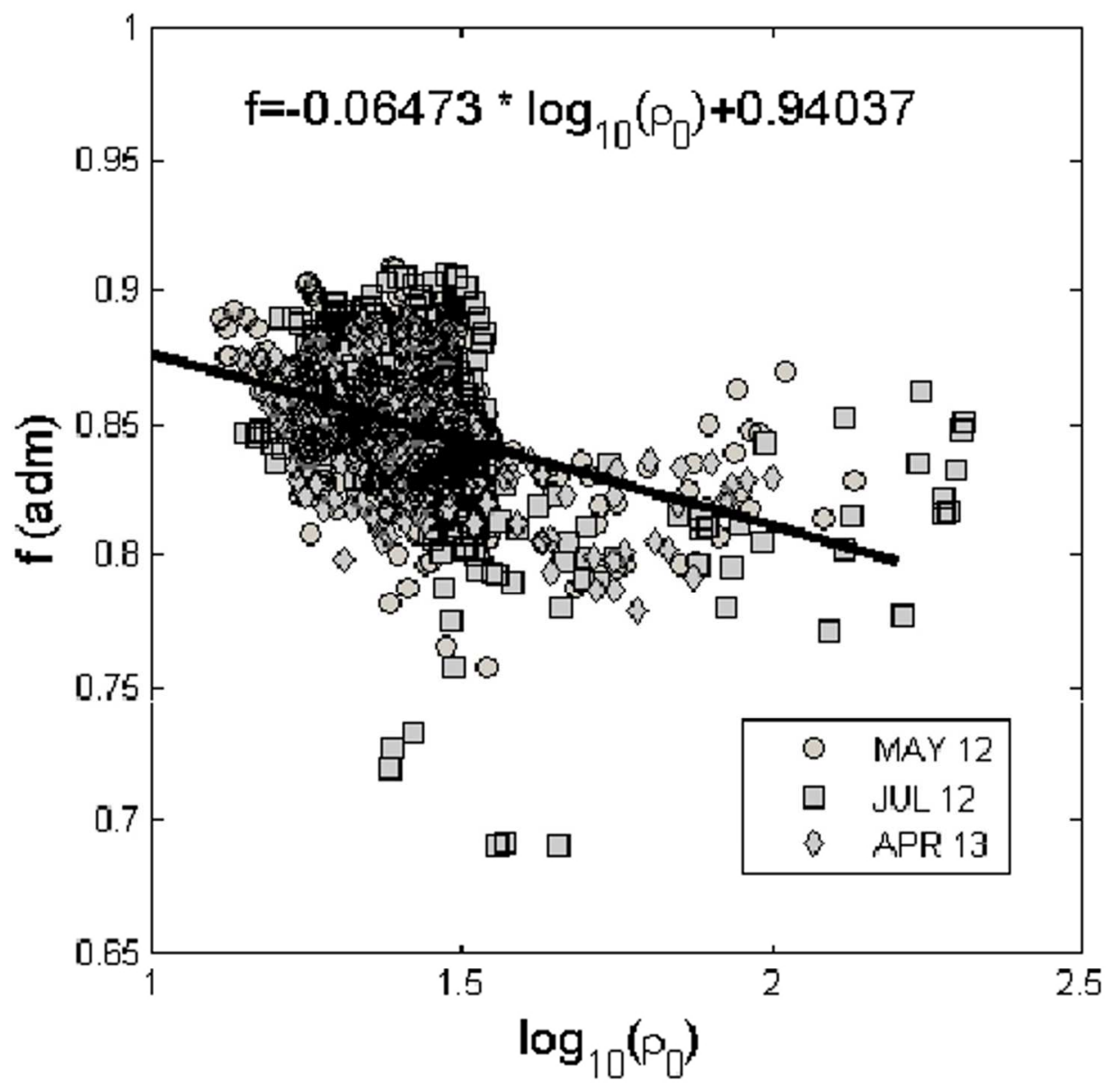

7. Conductivity partition parameter, $\mathrm{f}$, as a function of medium resistivity. Values between 0.7 and 0.9 suggest that bulk conductivity is the main contributor in the electrical conductivity, surface conductivity accounting with $10 \%$ to $30 \%$ of total conductivity.

$100 \times 96 \mathrm{~mm}(300 \times 300 \mathrm{DPI})$ 

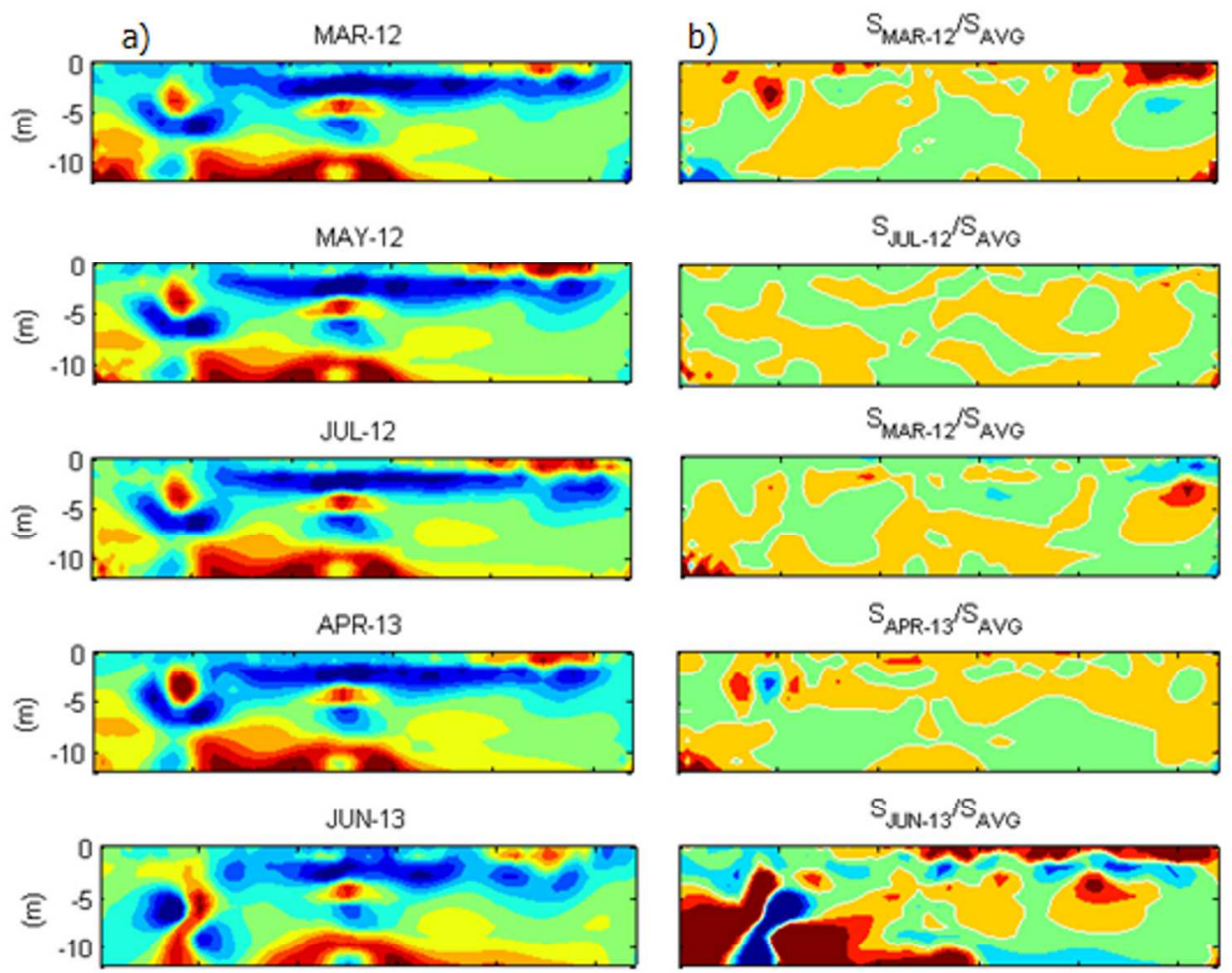

AVG
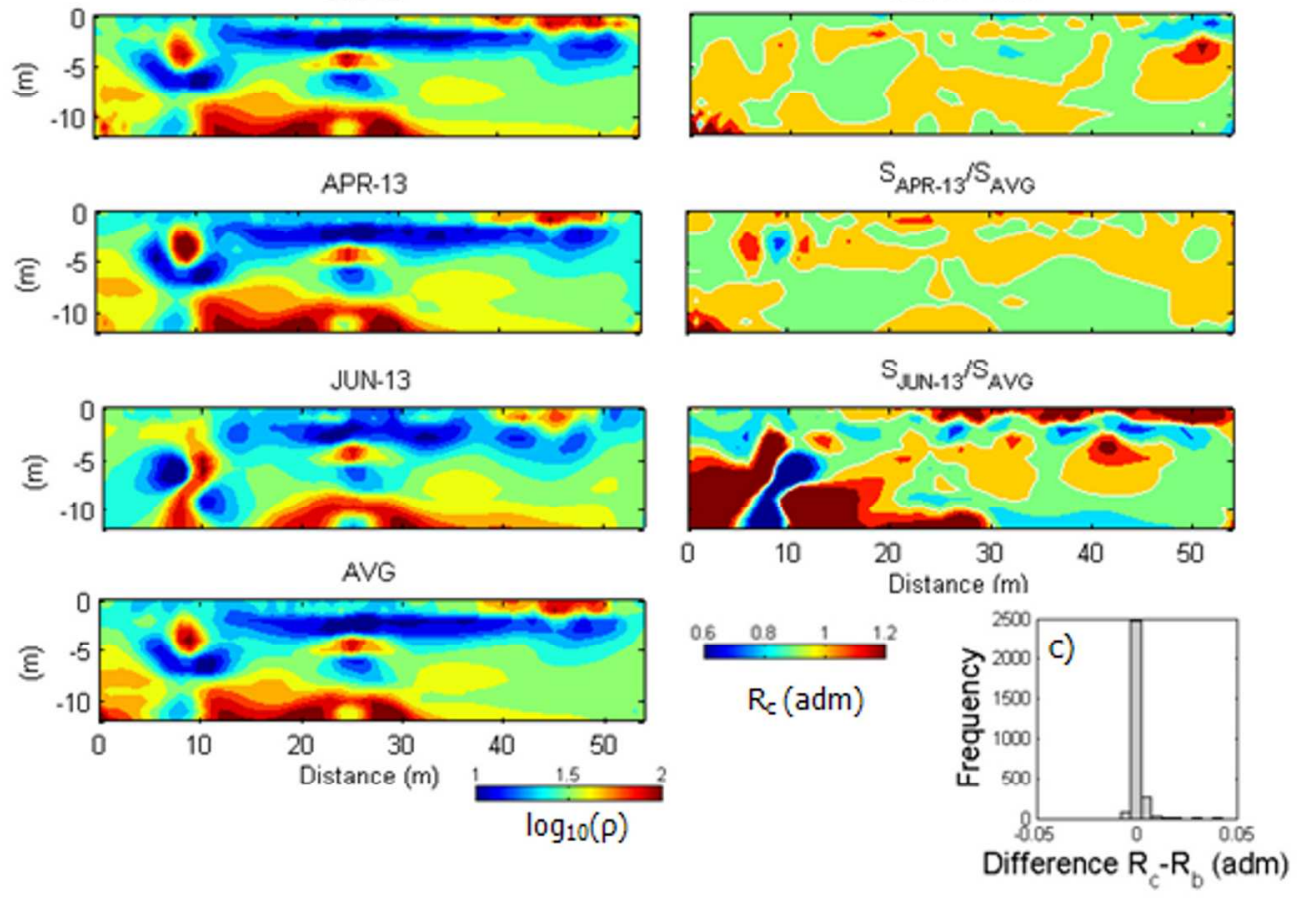

8. Resistivity sections (a) and resistivity ratios with respect to averaged (AVG) model (b). Unitary ratio contour line (white) delimits domains where Rc $>1$ (water saturation increases) and $R c<1$ (water saturation diminishes) with respect to AVG background model. Inset in (c) shows differences between assuming $f=1$

$(R b)$ or according empirical formula $f=-0.06473 * \log 10(\rho)+0.94037(R c)$. $169 \times 179 \mathrm{~mm}(300 \times 300 \mathrm{DPI})$ 


\section{Page 45 of 45}
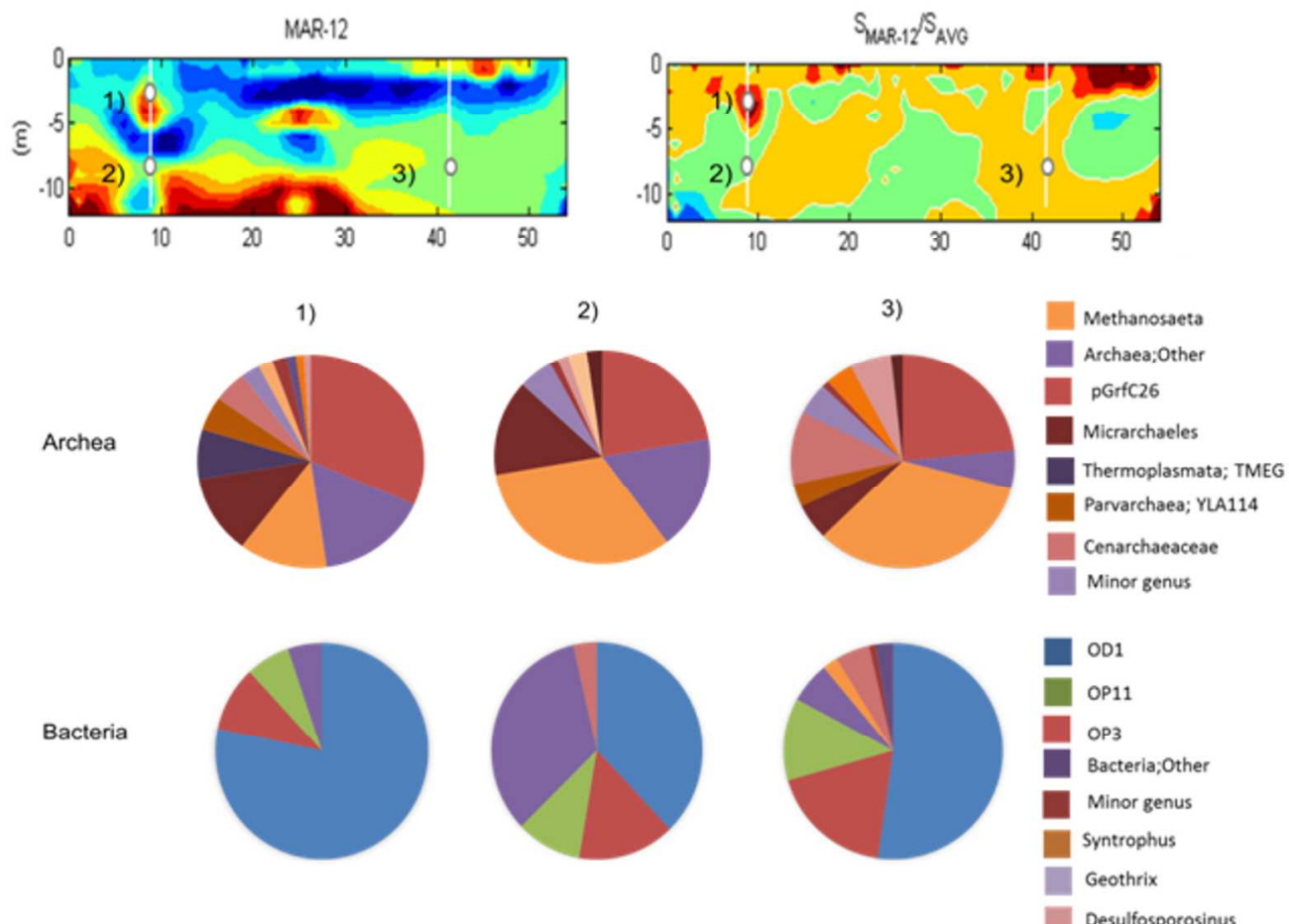

9. Bacterial and Archeal genus level taxonomic profile of suspended sediment in groundwater from different depths. Sample 1) was taken from depth of $2.5 \mathrm{~m}$ (waste deposits) and samples 2) and 3) are both taken from a depth of $8.4 \mathrm{~m}$ (fluvial sediment layer). $180 \times 139 \mathrm{~mm}(300 \times 300 \mathrm{DPI})$ 